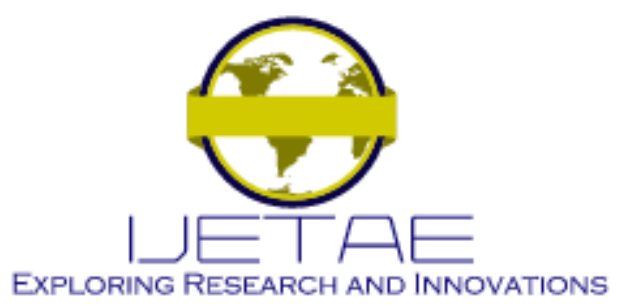

International Journal of Emerging Technology and Advanced Engineering

Website: www.ijetae.com (E-ISSN 2250-2459, Scopus Indexed, ISO 9001:2008 Certified Journal, Volume 12, Issue 01, January 2022)

\title{
Theoretical Study of Potential Manufacturing Insulation Defects in Medium-Voltage Traction Motors
}

\author{
Adoum Traoré Ndama ${ }^{1}$, Elysée Obame Ndong ${ }^{2}$, Yves Constant Mombo Boussougou ${ }^{3}$, Grace Jourdain Tsoumou ${ }^{4}$, \\ Eloi Jean Jacques Blampain ${ }^{5}$ \\ ${ }^{1,2,3}$ Masuku Electrical Engineering Laboratory (M2Elab), Département Génie Electrique, Université des Sciences et Techniques \\ de Masuku, Mbaya, route nationale, BP 941, Franceville Gabon \\ ${ }^{4,5}$ Laboratoire de Modélisation et Simulation de Composants (LMSC), Faculté des Sciences, USTM, Franceville Gabon, Faculté \\ des Sciences USTM Franceville B.P. 741 Gabon
}

\begin{abstract}
Medium-voltage motors dedicated to the applications of traction operate in an environment with strong multi-physics constraints. Electrical insulation of these engines is a complex multi-layered impregnated system which requires a given number of steps during the manufacturing process. In the present study, we theoretically investigated the potential manufacturing insulation defects of traction motors in low frequency domain. The aim is to assess the theoretical ability of dielectric spectroscopy method for the detection of these defects and the extension of the method to others insulation systems. The theoretical study is based on numerical modelling and simulation achieved by using Comsol Multiphysics software. In our numerical modelling the properties of the main dielectric elementary materials are frequency-dependent. The identification of each potential defect is carried out by comparing its equivalent capacitance and dissipation loss spectra with the characteristics of insulation without defect. As the results, all artificial defects are identifiable with a specific relative deviation. The detection of all the defects analysed will need a measuring device with resolution of $0.4 \%$.
\end{abstract}

Keywords-AC electric motors, Capacitance, dielectric, dissipation factor, composite insulation, numerical modelling.

\section{INTRODUCTION}

Traction motors work in environments with strong multi-physics constraints. Electrical insulating materials of these machines, are particularly subjected to high thermal and hygrometric stresses. Hence the need to ensure that electrical insulations leaving the factory contain a minimum of defects from reliable diagnostic tests since the economic losses associated with these defects can be considerable. For this reason, the development of techniques of monitoring and diagnostic to detect such failures is of paramount interest for reducing the failure rate and increasing the lifetime of electrical machines [1].
Thus several analysis methods of insulation systems in electrical machines, particularly stator induction motors, have been developed. These techniques are divided into online and off-line methods [1]. The off-line techniques is particularly interesting for monitoring and diagnosing elements of machine such as electrical insulation of stator during manufacturing process. Among off-line techniques there are destructive methods of diagnostic leading to the failure of insulation after tests, such as partial discharge (PD) and flashover voltage measurements [2-5] and nondestructive methods that include techniques such as measurement of insulation resistance and polarization index, infrared thermography [6].

PD is the most widely used method for the diagnosis of large motors and generators [7]. This method has widely been successfully used especially for the failure risk assessment of the low voltage motors containing various insulation artificial defects [5]. The method has served also to estimate the electrical machine insulation lifetime under the influence of environmental factors such as surrounding temperature, pressure, humidity [8]. Several other studies oriented to the detection of insulation faults of rotating machines have been carried out using the PD techniques [7, 9-11].

However the technique of partial discharge is seen to be strongly limited for the diagnosis of machines whose rated voltage is below $6 \mathrm{kV}$ and thus its suitable scope of use are large motors with rated voltages of $6 \mathrm{kV}$ and above [1]. So, other interesting techniques [12-16] such as power factor are available, but they present also some limitations.

Therefore the technique such as dielectric spectroscopy has been developed to complete the panel of insulation diagnostic methods. This technique of insulation diagnostic, has been evaluated on potential insulation defects [17-19]. 


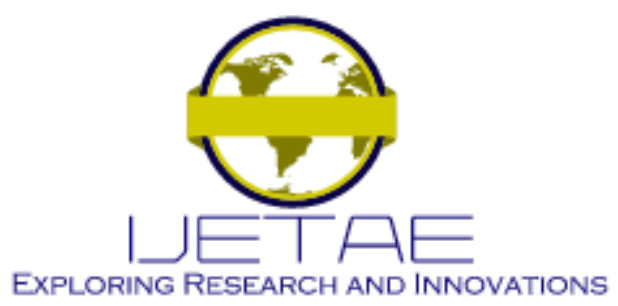

International Journal of Emerging Technology and Advanced Engineering

Website: www.ijetae.com (E-ISSN 2250-2459, Scopus Indexed, ISO 9001:2008 Certified Journal, Volume 12, Issue 01, January 2022)

The study of that method was based on the comparison of dielectric spectra of each defective model of stator with the spectra of the reference model in order to consider the ability of defect detection. The measurements carried out showed that aforementioned method is able to identify the wrong impregnation (no vacuum and no pressure phase) and non-impregnation defect types. Also, the not dried before impregnation and overlapping of the mica tape defects were less clearly identifiable [17]. However the kapton tearing out and no moistening mica tape before wrapping type defects remained not identifiable by the method. These results draw mixed conclusions on the effectiveness of dielectric spectroscopy as a diagnostic method. Moreover the accuracy of the method to identify potential defects is seen to be strongly influenced by humidity. In order better to appreciate the effectiveness of dielectric spectroscopy as a diagnostic method of electrical insulation defects, more in-deep evaluation is required. Theoretical study might allow particularly to predict the sensitivity of that method.

So, the aim of this study is to assess and predict the theoretical precision of spectroscopy technique from numerical modelling. Findings should allow the method to be extended to other electrical insulation systems and to improve the performance of dielectric spectroscopy measuring devices. The modelling and simulation are carried out using Comsol Multiphysics software in low frequency domain $(0.001 \mathrm{~Hz}$ to $100 \mathrm{~Hz})$. The choice of that frequency is in-line with experimental measurement performed by E. Obame et al [17]. The choice of that frequency range has been motivated to take into account the dielectric conduction and interfacial polarization phenomena which are predominant phenomena in that range [20, 21], insulation of traction motors being a complex multilayered impregnated system [17, 18, 22-24]. The theoretical dielectric spectra of each defective model will be compared to the spectra of the reference model noted M0 in order to consider the ability of defect detection. Qualitative analysis of the observed deviations will be proposed for each defect. Eventually, all the spectra will be compared for identification purpose.

\section{Modelling AND SimUlation}

Modelling of electrical insulation of stator coil for AC traction motors is carried out taking into account the electrical insulation of stator models designed by Alstom Transport (Figure. 1).

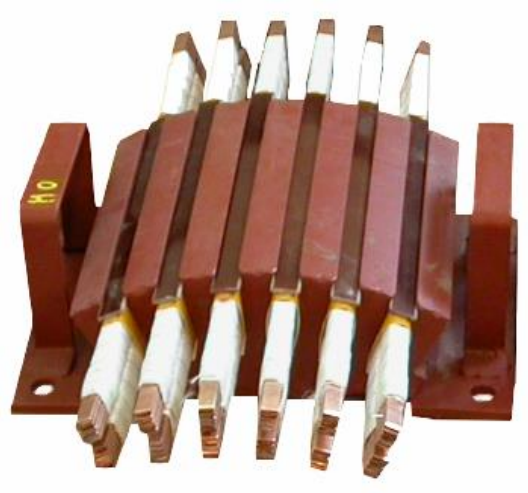

a)

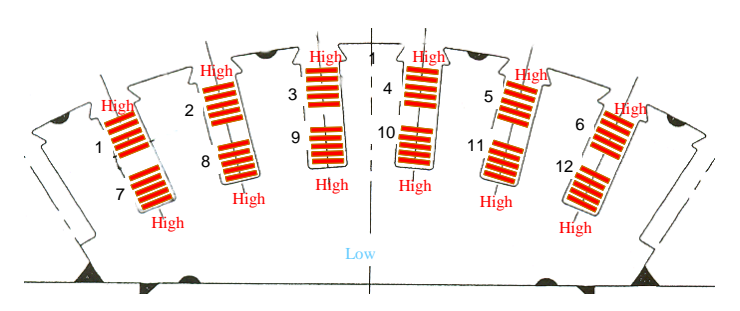

b)

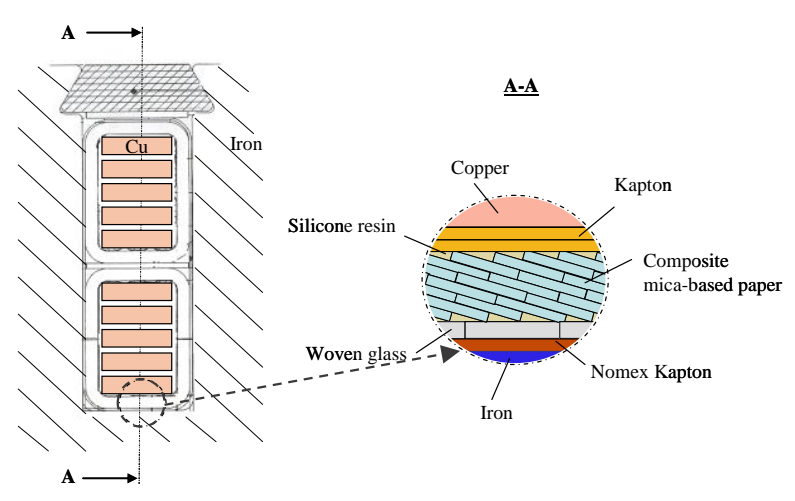

c)

Figure 1. Model stator for ac traction motors of Alstom transport. a) Model tested consisting in a section of a stator with inversed curvature, b) cross section of the model with the connections, c) left: cross section of the slot. Right: stratigraphy of the insulating composite (principle).

The theoretical sensitivity of spectroscopy is evaluated from dielectric modelling based on the physical properties of the elementary materials constituting the composite insulation of traction motor. 


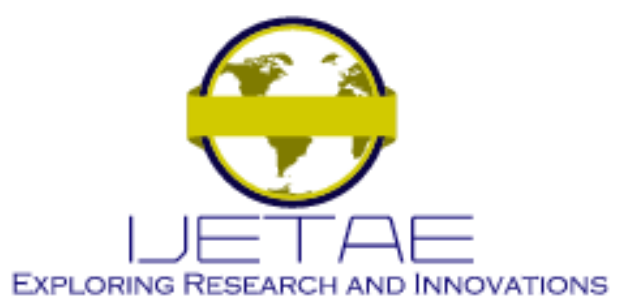

International Journal of Emerging Technology and Advanced Engineering

Website: www.ijetae.com (E-ISSN 2250-2459, Scopus Indexed, ISO 9001:2008 Certified Journal, Volume 12, Issue 01, January 2022)

This modelling and simulation work is carried out on Comsol Multiphysics software in a frequency range going from $0.001 \mathrm{~Hz}$ to $100 \mathrm{~Hz}$. The model analysis is based on two relevant parameters, the equivalent capacitance of the composite electrical insulation and the dissipation factor $\tan \delta$.

\section{A. Description of the model}

Electrical insulation of components or systems is generally subjected to electric potential difference between two metallic parts. The electrical system thus constituted can be modelled as a capacitor with two electrodes, one of them subjected to electric potential and the other grounded.

In the case of electrical traction motor, coil conductors of the three-phase windings are subjected to electrical potential and the iron constituting the magnetic circuit of the machine is grounded. The model adopted in our theoretical study is a simple two parallel plane electrodes capacitor $[25,26]$ in $2 \mathrm{D}$. The insulation of coil conductors is lied between two plane electrodes constituting by copper coil conductor and iron of magnetic circuit. The architecture of that insulation is that seen in Figure 1c [17] (stratigraphy of the insulating composite). The structure of stator composite insulation model geometry is then shown in Figure 2. This model geometry (Figure 2) takes into account the real geometry dimension of each elementary dielectric material.

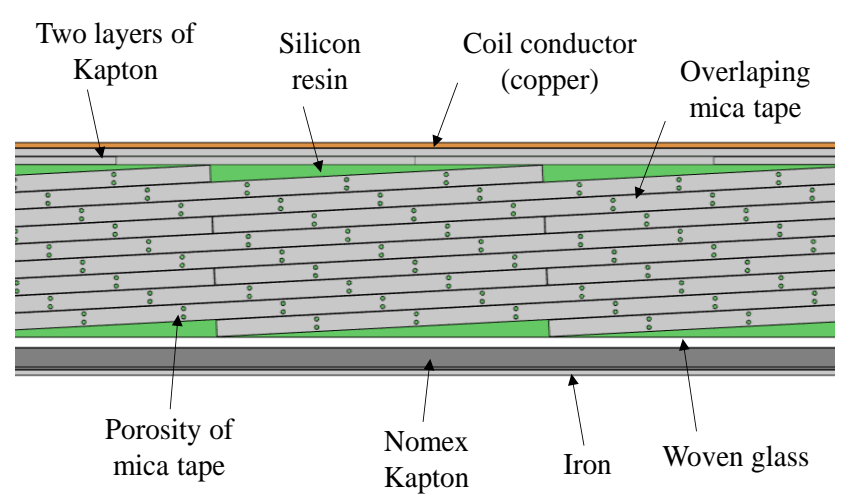

Figure 2. Model geometry of electrical composite insulation (reference stator model

In order to simplify the geometry of the insulation simulated in the context of this study, the tape Samicapor (composite mica-based paper) is considered rigid laterally. The different layers of this material are therefore modelled by superimposed rectangles respecting the different levels of overlap considered in this study.
The porosity of this material is taken into account in the imperfection of the contact created between different layers of the tape and holes located inside the material.

The winding of the stator coil conductors with Samicapor tape is carried out by three (3) layers with $2 / 3$ overlap [19] on the reference model (Figure 1c). This wrapping is taken into account by tilting the tape with an angle of $3^{\circ}$.

To take into account the imperfection of contact between different dielectric materials constituting the insulation of our stator, a tiny space of $5 \mu \mathrm{m}$ has been integrated between elementary dielectrics material layers. The choice of this dimension was strongly influenced by the minimum size of the mesh allowing a satisfactory resolution of the physics of the problem with an allowable computation time.

Electrical insulation of the stator is impregnated by silicon resin. To take into account that impregnation our insulation system is contained in a rectangle which the affected material is silicone resin (Figure 2).

Table I gives the materials of our two parallel planes capacitor model and their relevant parameters for geometry construction. The main electrical characteristics of these materials involved in our simulation are also given.

TABLE I

GEOMETRIC AND ELECTRICAL MAIN PARAMETERS OF ELEMENTARY MATERIALS OF OUR PLAN TO PLAN CAPACITOR MODEL

\begin{tabular}{|c|c|c|}
\hline Materials & $\begin{array}{c}\text { Thickness } \\
(\mu \mathrm{m})\end{array}$ & $\begin{array}{c}\text { Main } \\
\text { characteristics }\end{array}$ \\
\hline Copper (electrode high) & 50 & \multirow{8}{*}{$\begin{array}{l}\text { Dielectric relative } \\
\text { permittivity } \varepsilon \\
\text { and electrical } \\
\text { conductivity } \sigma \text { or } \\
\text { dissipation factor } \\
\tan \delta\end{array}$} \\
\hline Epoxy resin & 5 & \\
\hline Kapton & 75 & \\
\hline Samicapor tape & 160 & \\
\hline Nomex & 180 & \\
\hline Glass ribbon & 100 & \\
\hline Nomex-Kapton & 25 & \\
\hline Iron (electrode low) & 50 & \\
\hline
\end{tabular}

The total length and thickness of our plane to plane capacitor model geometry are $30 \mathrm{~mm}$ and $2.215 \mathrm{~mm}$ respectively. For illustration purpose the total length in Figure 2 is cut to better see the arrangement of elementary materials in the insulation system. Modelling of our capacitor is carried out in $2 \mathrm{D}$ and simulations performed in frequency domain by using the AC/DC module of Comsol Multiphysics Software. 


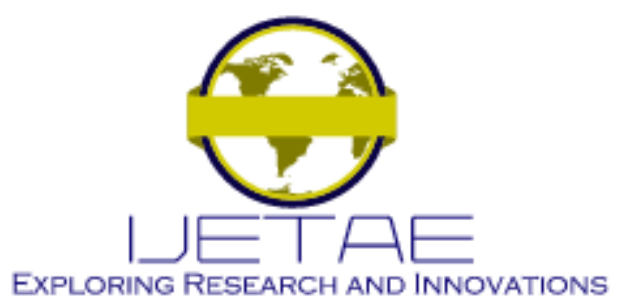

International Journal of Emerging Technology and Advanced Engineering

Website: www.ijetae.com (E-ISSN 2250-2459, Scopus Indexed, ISO 9001:2008 Certified Journal, Volume 12, Issue 01, January 2022)

\section{B. Electrical properties of materials used in our modelling}

Electrical characteristics of elementary materials used in our simulation were obtained essentially from measurements performed by Obame et al [19]. These characteristics are used as the function of frequency to be closed to the experimental reality.

1). Kapton: The HN Kapton type has been used in our application [17-19, 27, 28]. The frequency behaviour of the relative permittivity $(\varepsilon)$ and dissipation factor $(\tan \delta)$ of that dielectric material are given in Figure 3 and Figure 4.

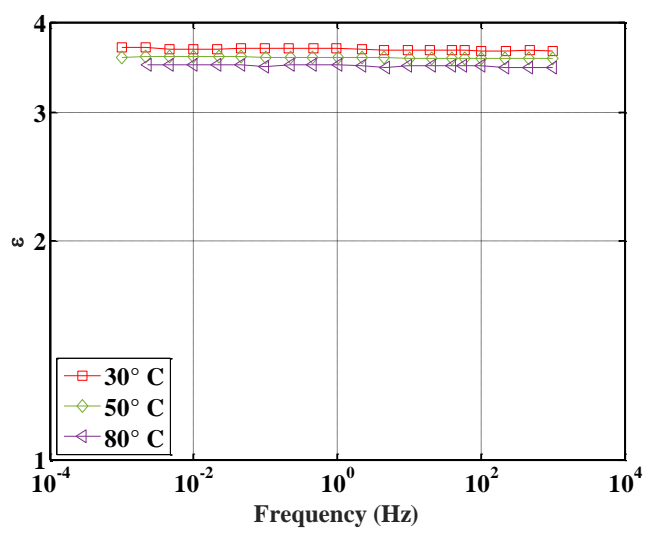

Figure 3. Relative permittivity of Kapton as a function of frequency for different temperatures.

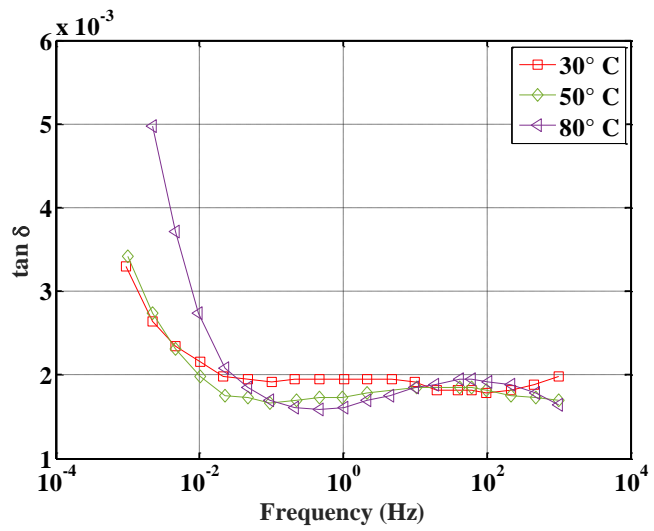

Figure 4. Dissipation factor tano of Kapton as a function of frequency for different temperatures.

For our modelling purpose, we used linear approximation of these characteristics at $30^{\circ} \mathrm{C}$ as variables. Thus the relative permittivity and dissipation factor $\tan \delta$ used in our simulation as variables are given by relations (1) and (2) obtained from Matlab software.
The coefficients of these relations come from the fit of Obame et al data [19] and are available in Table II.

$$
\begin{gathered}
\varepsilon(f)=\sum_{k=0}^{7}\left[A_{k} \cos (k \omega f)+B_{k} \sin (k \omega f)\right] \\
\tan \delta(\mathbf{f})=\sum_{\mathbf{k}=0}^{7} \mathbf{C}_{\mathbf{k}} \times \mathbf{f}^{\mathbf{k}} \\
\text { TABLE II }
\end{gathered}
$$

COEFFICIENTS OF THE LINEAR APPROXIMATION OF RELATIVE PERMITTIVITY AND DISSIPATION FACTOR OF KAPTON. THE FIT PARAMETERS SUCH AS SSE, R-SQUARE, ADJUSTED R-SQUARE, AND RMSE FOR PERMITTIVITY ARE 8.987, 1, 0.9999, AND 0.001499 RESPECTIVELY AND THESE OF DISSIPATION FACTOR ARE: SSE = $2.485 .10^{-8}$, R-SQUARE $=0.9981$, ADJUSTED R-SQUARE $=0.997$ AND RMSE $=4.551 .10^{-5}$.

\begin{tabular}{|c|c|c|c|}
\hline $\mathbf{k}$ & $\mathbf{A}_{\mathbf{k}}$ & $\mathbf{B}_{\mathbf{k}}$ & $\mathbf{C}_{\mathbf{k}}$ \\
\hline 0 & 2634 & 0 & 1.0045 \\
\hline 1 & 134.3 & -117.1 & $7.26310^{-5}$ \\
\hline 2 & -97.65 & 91.46 & $-1.0110^{-4}$ \\
\hline 3 & -97.65 & -60.40 & $-9.18810^{-5}$ \\
\hline 4 & 81.85 & 32.81 & $2.23210^{-5}$ \\
\hline 5 & -62.77 & -21.30 & $9.47510^{-6}$ \\
\hline 6 & 53.18 & 21.79 & $9.56110^{-7}$ \\
\hline 7 & 5.961 & 5.119 & $-7.22210^{-7}$ \\
\hline
\end{tabular}

One can note that the resistivity Kapton is $1.410^{17} \Omega \mathrm{cm}$ [19]. It was taken has constant in our modelling.

2). Nomex-Kapton: For our simulation dielectric characteristics of Nomex-Kapton namely $\varepsilon$ and $\tan \delta$ are given by relations (3) and (4) obtained by fitting the data of Figure 5 and Figure 6 [19]. The coefficients of these relations are shown in Table III.

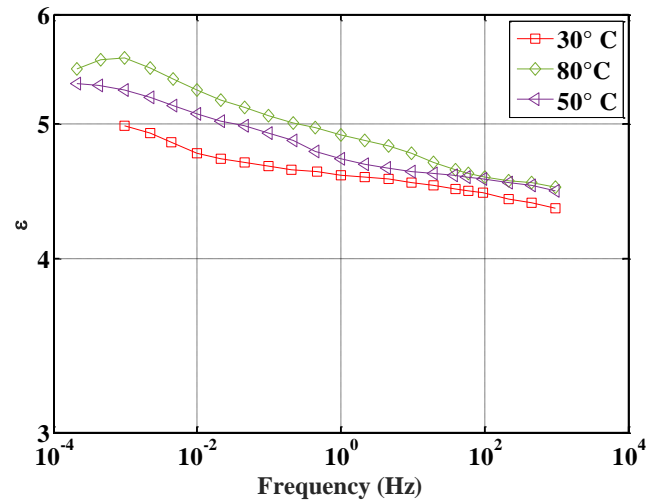

Figure 5. Relative permittivity of Nomex-Kapton as a function of frequency for different temperatures. 


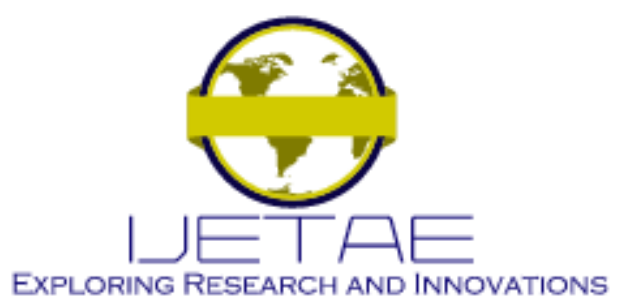

International Journal of Emerging Technology and Advanced Engineering

Website: www.ijetae.com (E-ISSN 2250-2459, Scopus Indexed, ISO 9001:2008 Certified Journal, Volume 12, Issue 01, January 2022)

TABLE IV

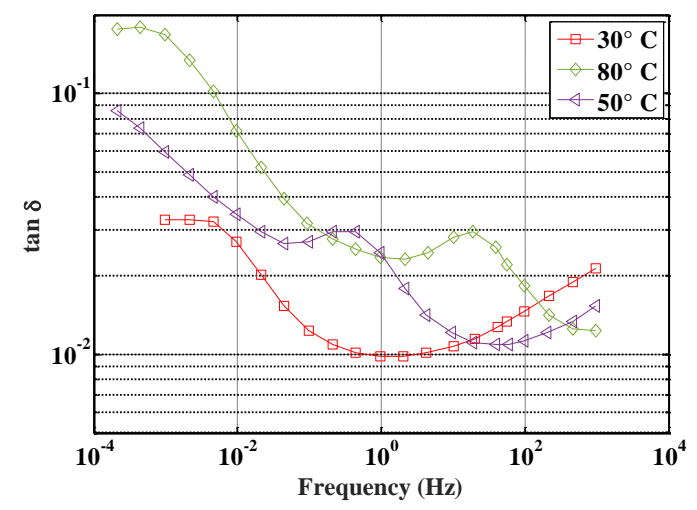

Figure 6. Dissipation factor tan $\delta$ of Nomex-Kapton as a function of frequency for different temperatures

$$
\begin{aligned}
& \varepsilon(f)=\sum_{k=0}^{g} D_{k} \times f^{k} \varepsilon \\
& \tan \delta(f)=\sum_{k=0}^{6}\left[E_{k} \cos (k \omega f)+F_{k} \sin (k \omega f)\right]
\end{aligned}
$$

TABLE III

COEFFICIENTS OF THE LINEAR APPROXIMATION OF RELATIVE PERMITTIVITY AND DISSIPATION FACTOR OF NOMEX - KAPTON. THE FIT PARAMETERS SUCH AS SSE, R-SQUARE, ADJUSTED R-SQUARE, AND RMSE FOR PERMITTIVITY ARE 8.691.105, 0.9999, 0.9998, AND 281.1 RESPECTIVELY AND THESE OF DISSIPATION FACTOR ARE: SSE = $1.339 .10^{-7}$, R-SQUARE $=1$, ADJUSTED R-SQUARE $=0.9999$ AND RMSE $=$ $1.49410^{-4}$.

\begin{tabular}{|c|c|c|c|}
\hline $\mathbf{k}$ & $\mathbf{D}_{\mathbf{k}}$ & $\mathbf{E}_{\mathbf{k}}$ & $\mathbf{F}_{\mathbf{k}}$ \\
\hline 0 & -10.80 & 2.355 & 0 \\
\hline 1 & 23.27 & -2.351 & -0.2462 \\
\hline 2 & 158.5 & 1.644 & 0.3443 \\
\hline 3 & -378.1 & -0.9092 & -0.3029 \\
\hline 4 & -366.6 & 0.3638 & 0.1862 \\
\hline 5 & 771.1 & -0.0896 & -0.07051 \\
\hline 6 & -5934 & - & - \\
\hline 7 & 37090 & - & - \\
\hline
\end{tabular}

The resistivity of the nomex measured by E. Obame et al at $30^{\circ} \mathrm{C}$ is $610^{11} \Omega \mathrm{cm}[19]$. This magnitude is also taken as a constant in our simulations.

3). Samicapor tape: Samicapor n॰43220 tape used in winding insulation consists of a sheet of $120 \mathrm{~g} / \mathrm{m}^{2}$ samica impregnated and agglomerated on a $25 \mathrm{~g} / \mathrm{m}^{2}$ silicone support with a special silicone-based resin [17, 19]. The characteristics of that material are given in Table IV.
CharaCteristics OF MiCACEOUS TAPE

\begin{tabular}{|l|c|c|}
\hline Physical properties & values & unit \\
\hline Thickness & 0.16 & $\mathrm{~mm}$ \\
\hline Thickness tolerance & \pm 0.03 & $\mathrm{~mm}$ \\
\hline Average weight per unit area & $210 \pm 20$ & $\mathrm{~g} / \mathrm{m}^{2}$ \\
\hline Minimum mica content & 49 & $\%$ \\
\hline Tensile strength & $100 \pm 20$ & $\mathrm{~N} / \mathrm{cm}$ \\
\hline
\end{tabular}

Samicapor tapes are usually supplied in widths from 10 $\mathrm{mm}$ [29]. In our simulation the relative permittivity of Samicapor takes the value of $6[19,30]$ and its conductivity is $10^{-10} \Omega / \mathrm{m}$ [30] (Table $\mathrm{V}$ ). These values are taken as constants because of the frequency dependence unavailability of these data in literature.

TABLE V

DIELECTRIC CHARACTERISTICS OF THE MATERIALS USED IN OUR

\begin{tabular}{|c|c|c|c|c|}
\hline \multirow[b]{2}{*}{$\begin{array}{l}\text { Material } \\
(1 \mathrm{kHz})\end{array}$} & \multicolumn{2}{|c|}{ Tan $\delta\left(10^{-3}\right)$} & \multicolumn{2}{|c|}{ Relative permittivity $\varepsilon$} \\
\hline & $\begin{array}{l}\text { Data sheet } \\
\text { at } 23^{\circ} \mathrm{C} \text {, } \\
50 \% \mathrm{RH}\end{array}$ & $\begin{array}{l}\text { Measure } \\
\text { at } 30^{\circ} \mathrm{C}\end{array}$ & $\begin{array}{c}\text { Data } \\
\text { sheet at } \\
23^{\circ} \mathrm{C}, \\
50 \% \mathrm{RH}\end{array}$ & $\begin{array}{l}\text { Measure } \\
\text { at } 30^{\circ} \mathrm{C}\end{array}$ \\
\hline Kapton & 2 & $1.98 \pm 5$ & 3.5 & $3.4 \pm 0.02$ \\
\hline $\begin{array}{l}\text { Nomex- } \\
\text { Kapton }\end{array}$ & - & $20 \pm 5$ & - & $4.4 \pm 0.03$ \\
\hline $\begin{array}{l}\text { Silicon } \\
(50 \mathrm{~Hz})\end{array}$ & 4 & & 2.9 & \\
\hline Mica & 20 & - & $6-6.6$ & - \\
\hline
\end{tabular}
SIMULATIONS $[17,19]$

The relative permittivity and conductivity of woven glass material in our computational model has been assimilated to that of glass $\left(2.7[31,32]\right.$ and $10^{-15} \mathrm{~S} / \mathrm{m}$ [33] respectively) because the characteristics of that material as a function of frequency were not available in literature. And the influence of that material in our computational model is seen to be weak since it is not affected by any defect. For silicon resin, the relative permittivity and the electrical resistivity used are 4.2 and $5.10^{15} \Omega . \mathrm{cm}$ respectively [34].

\section{Boundary conditions and mesh}

Boundary conditions of our study are those defined by the applied electric potential on either side of the modelled insulation system. 


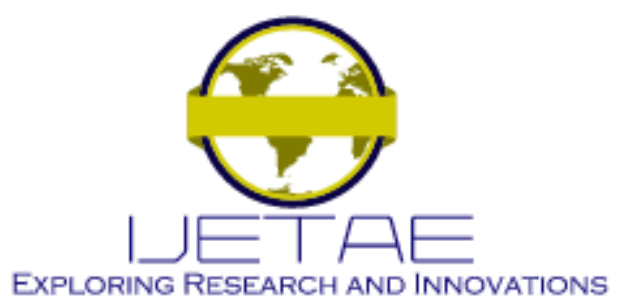

International Journal of Emerging Technology and Advanced Engineering

Website: www.ijetae.com (E-ISSN 2250-2459, Scopus Indexed, ISO 9001:2008 Certified Journal, Volume 12, Issue 01, January 2022)

The copper (coiled conductors) is the electrode subjected to electric potential of $200 \mathrm{~V}$ and the iron constituting the magnetic circuit of the model stator is grounded (Figure 7). The magnitude of the electric potential subjected to the copper coil is in-line with the experimental measurement performed in [17].

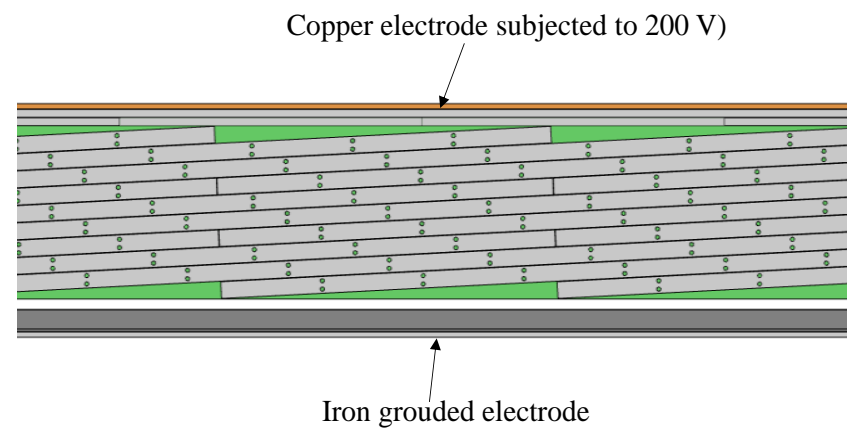

Figure 7. Boundary condition of the simulated model M0

The mesh of our model is presented in Figure 8. The mesh used in our study is the extremely fine type and we used triangular meshes. This allowed a sufficiently dancing mesh with a reasonable resolution time and relatively good precision.

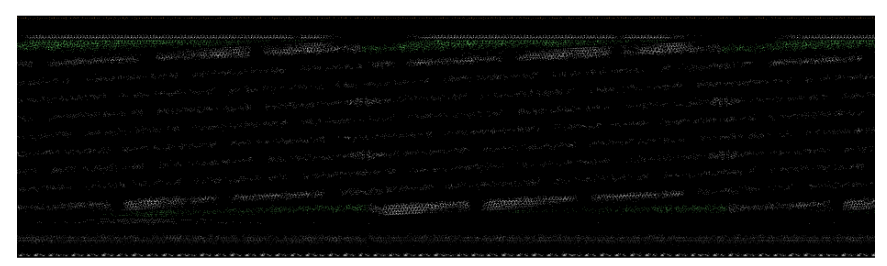

Figure 8. Mesh of the model

For our computational model, the equations solved by Comsol Multiphysics are given by relations (5-7).

$$
\begin{aligned}
& \vec{\nabla} \times \vec{\jmath}=Q_{j V} \\
& \vec{l}=\sigma \times \vec{E}+j \omega \times \vec{D}+\vec{J}_{e} \\
& \vec{E}=-\vec{\nabla} V
\end{aligned}
$$

Where $\mathbf{J}$ is the total current density, $\mathrm{Q}_{\mathrm{J}, \mathrm{V}}$ is the total charge of the carriers, $\mathbf{J}_{\mathbf{e}}$ the diffusion current, $\mathrm{V}$ the electric potential, $\mathbf{D}$ is the electrical displacement and $\mathbf{E}$ the electric field.

\section{Simulation Results For The Model Without DEFECT (REFERENCE M0)}

The results of the modelling are shown as electric potential distribution in the composite insulation of reference model M0 and frequency spectra of equivalent capacitance $\mathrm{C}$ and dissipation factor $\tan \delta$.

\section{A. Electric potential distribution in motor composite insulation}

Figure 9 gives electric potential distribution in the composite insulation of the motor for reference insulation model (model without defect noted M0) for a fixed frequency of $0.001 \mathrm{~Hz}$. To take into account the influence of the contact between different elementary dielectric materials, a small gap is introduced between each layer of elementary dielectric materials. The composite insulation being impregnated, this gap is filled with silicone resin. The influence of that contact has been investigated during the validation of the model (Table VI). And it was shown that the influence of the contact gap on the capacitance and $\tan \delta$ remains weak (for a contact gap varying from $5 \mu \mathrm{m}$ to $20 \mu \mathrm{m}$, changes in capacitance and $\tan \delta$ are lower than 0.01 $\%$ and $0.5 \%$ respectively).

Investigations of electrical insulation defects conducted in the present work has been led with a contact gap of $5 \mu \mathrm{m}$.

TABLE VI

INFLUENCE OF THE CONTACT BETWEEN ELEMENTARY DIELECTRIC MATERIALS ON CAPACITANCE AND DISSIPATION FACTOR OF THE COMPOSITE INSULATION OF MOTOR

\begin{tabular}{|l|c|c|}
\hline $\begin{array}{l}\text { Contact gap } \\
(\boldsymbol{\mu m})\end{array}$ & Capacitance $(\mathbf{p F})$ & $\begin{array}{c}\text { Dissipation factor } \\
\tan \boldsymbol{\delta}\left(\mathbf{1 0}^{-\mathbf{3}}\right)\end{array}$ \\
\hline 5 & 1593.8 & 0.4044 \\
\hline 15 & 1593.2 & 0.4054 \\
\hline 25 & 1592.4 & 0.4064 \\
\hline
\end{tabular}

One can observed (Figure 9) that electric potential is logically higher near the copper electrode (HV electrode) and it decreases towards the grounded electrode. It is also noticed that the distribution of electric potential is inhomogeneous in insulation system owing of the composite structure of the motor electrical insulation. 


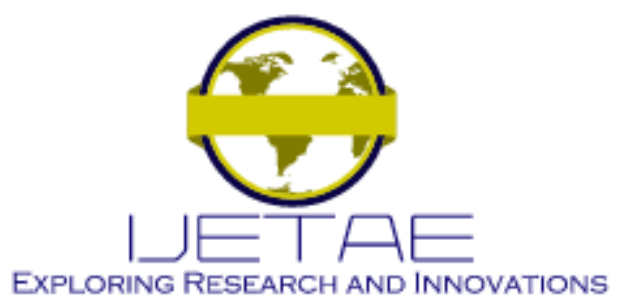

International Journal of Emerging Technology and Advanced Engineering

Website: www.ijetae.com (E-ISSN 2250-2459, Scopus Indexed, ISO 9001:2008 Certified Journal, Volume 12, Issue 01, January 2022)

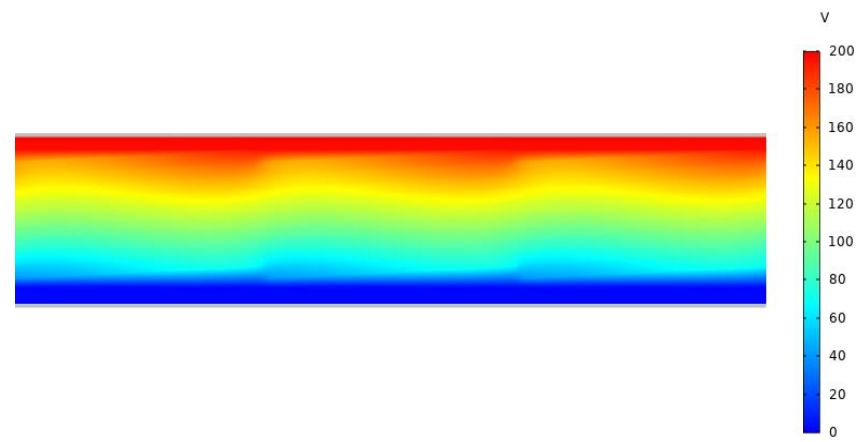

Figure 9. Electric potential distribution in motor composite insulation

\section{B. Influence of frequency on electric potential distribution}

Figure 10 shows the distribution of electric potential for different frequencies of $0.001 \mathrm{~Hz}, 100 \mathrm{~Hz}$ and $1 \mathrm{kHz}$. It is seen a weakening of potential gradient with the frequency increase. We can also notice that the effect of inhomogeneity of the potential inside the insulation system decreases with the increasing of frequency. This can be explained by the weakening of the influence of electrical conductivity in favour of the capacitive effect when the frequency increases.

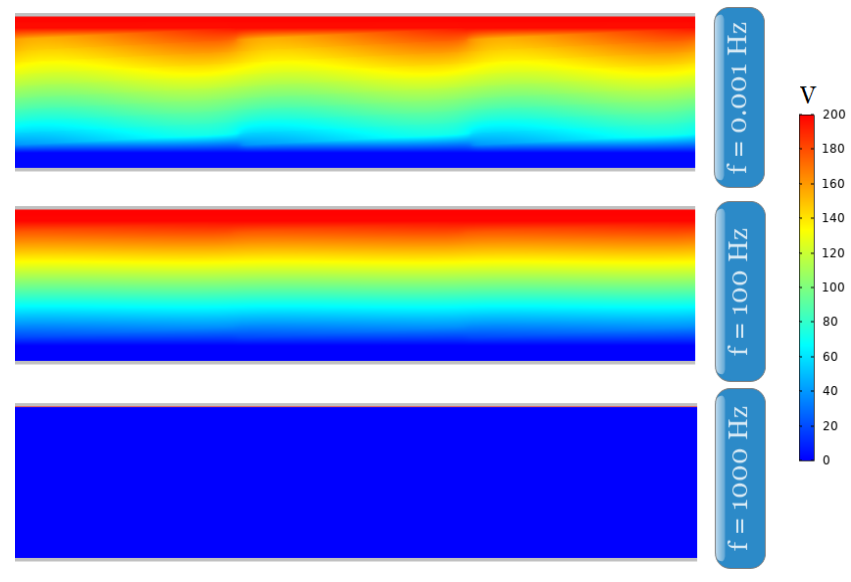

FIGURE 10. Electric potential distribution for different frequencies of $0.001 \mathrm{~Hz}, 100 \mathrm{~Hz}$ and $1 \mathrm{kHz}$.

\section{Reference model MO capacitance and dissipation factor spectra}

Figure 11 shows the behaviour of the capacitance and the dissipation factor $\tan \delta$ of the reference model insulation as the function of frequency. One can observe that the insulation capacitance (Figure 11a) decreases from 0.001 to $0.01 \mathrm{~Hz}$. Above $0.01 \mathrm{~Hz}$ the capacitance shows a plateau up to $100 \mathrm{~Hz}$.
The increase of the capacitance at low frequencies is generally explained by DC conduction phenomenon [35, 36] and the plateau seen between $0.01 \mathrm{~Hz}$ and $100 \mathrm{~Hz}$ testifies to the pure capacitance behaviour, DC conduction being relatively low in that range of frequency. Note that polarization was not taken into account in our computational model.

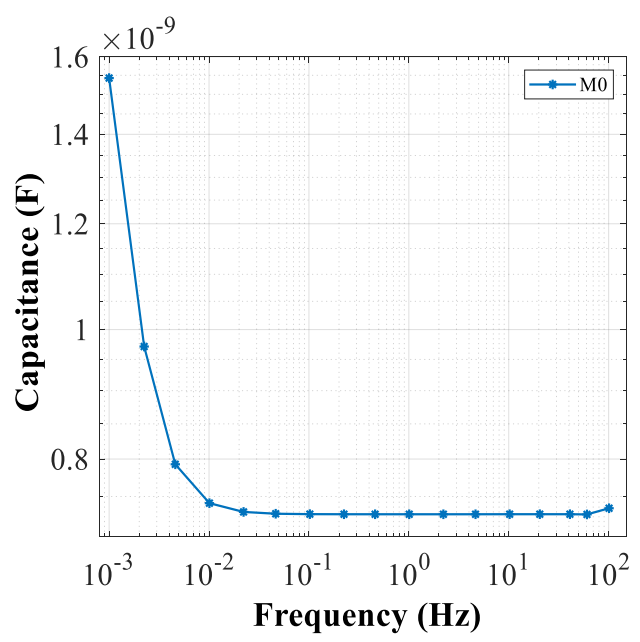

a)

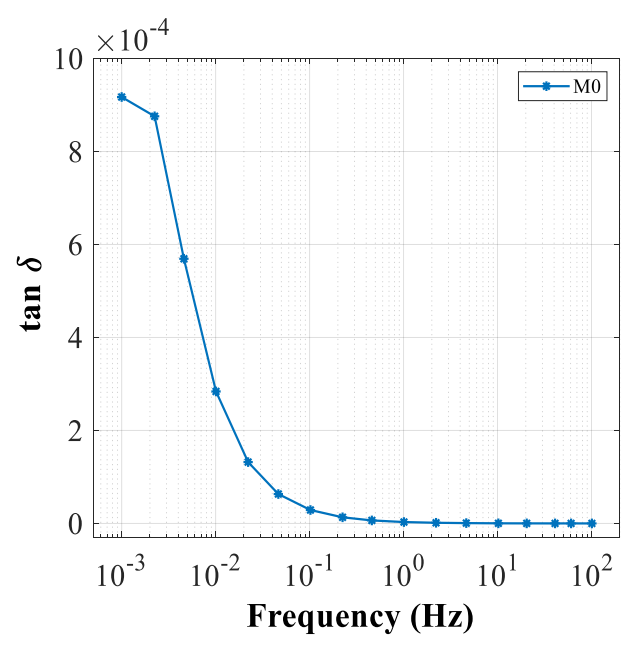

b)

Figure 11. Frequency behavior of the dielectric characteristics of motor insulation, a) capacitance, b) dissipation factor $\tan \delta$ 


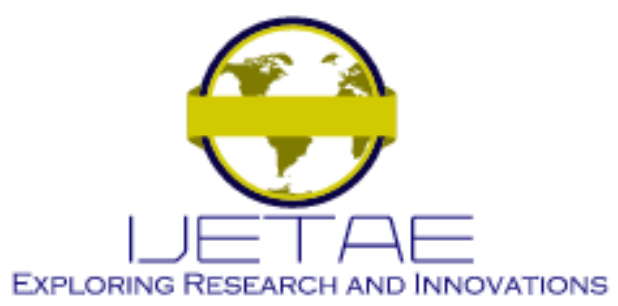

International Journal of Emerging Technology and Advanced Engineering

Website: www.ijetae.com (E-ISSN 2250-2459, Scopus Indexed, ISO 9001:2008 Certified Journal, Volume 12, Issue 01, January 2022)

The relative precision of our computational model is $10^{-6}$ defined by the ratio of the imaginary to the real part of the admittance constituting by the composite insulation of the motor. The maximum frequency providing very good accuracy in our calculation was then limited to $61,282 \mathrm{~Hz}$ that is why our frequency of study has been limited to 100 $\mathrm{Hz}$ (decade containing $60 \mathrm{~Hz}$ ).

In Figure 11b, it is observed that dissipation factor tan $\delta$ logically increases at low frequencies testifying to the influence of electrical conductivity. Tan $\delta$ shows a plateau for frequencies above $1 \mathrm{~Hz}$. The lack of polarization phenomena in our calculations can explain that behaviour.

\section{InVESTigation Of Medium Voltage Motor DIELECTRIC INSULATION DEFECTS}

Defects investigated here are those could be encountered during manufacturing processes $[17,18]$. The study of motor electrical insulation defects on Comsol Multiphysics is subjected to the same calculation process as that made with the model M0 previously investigated (section II and III). However, the insulation containing a defect led to a modification of the composite insulation geometry structure. Thus we present in this part the geometry structure adopted for each defect and then the computational results of simulation (i.e. spectra of capacitance and $\tan \delta$ ) in comparison with the model M0 results.

The potential electrical insulation defects investigated in this study are seen in Table VII.

TABLE VII

LIST OF ARTIFICIAL DEFECTS MODELLED

\begin{tabular}{|c|c|}
\hline Model & Electrical Insulation defect \\
\hline M0 & Flawless reference \\
\hline M1a & Weaker overlapping of samicapor tape \\
\hline M1b & Medium overlapping of samicapor tape \\
\hline M2 & Kapton tearing \\
\hline M3 & $\begin{array}{c}\text { Wrong impregnation (no vacuum and no pressure } \\
\text { phase) }\end{array}$ \\
\hline M4 & No impregnation \\
\hline M5 & No dried before impregnation \\
\hline M6 & No moistening of the mica tape before wrapping \\
\hline
\end{tabular}

\section{A. Samicapor overlapping tape defect (MI)}

The samicapor overlapping tape defect is made by weaker overlapping with two layers of $1 / 2$ overlapping noted M1a and middle overlapping with two layers of $2 / 3$ overlapping M1b knowing that the good overlapping tape is considered with three layers of $2 / 3$ samicapor tape as seen in Figure 1c [17].

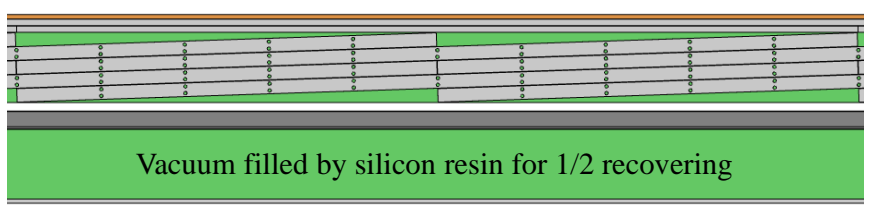

a)

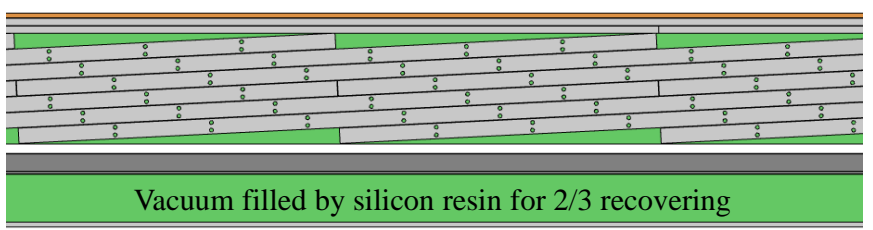

b)

Figure 12. Model geometry of Samicapor tape recovering defect, a) $1 / 2$ recovering $M 1 a, b)$ 2/3 recovering M1b.

Figure 12 show the model geometries adopted for these insulation defects. The size of stator slots being unchanged, these defects lead to a vacuum in composite electrical insulation of the stator that is filled by silicon resin during impregnation process. This vacuum results from the reduction of the Samicapor tape overlapping thickness.

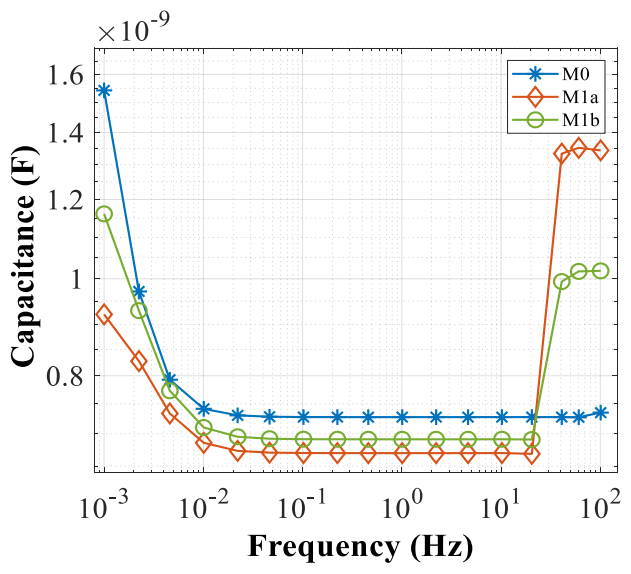

a) 


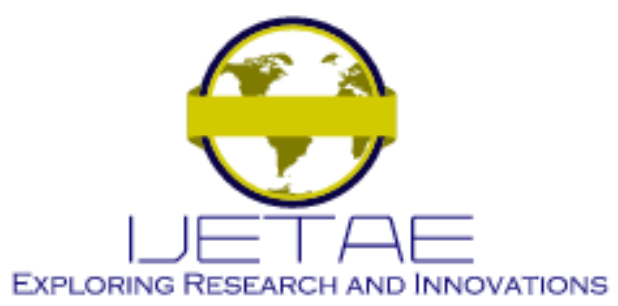

International Journal of Emerging Technology and Advanced Engineering

Website: www.ijetae.com (E-ISSN 2250-2459, Scopus Indexed, ISO 9001:2008 Certified Journal, Volume 12, Issue 01, January 2022)

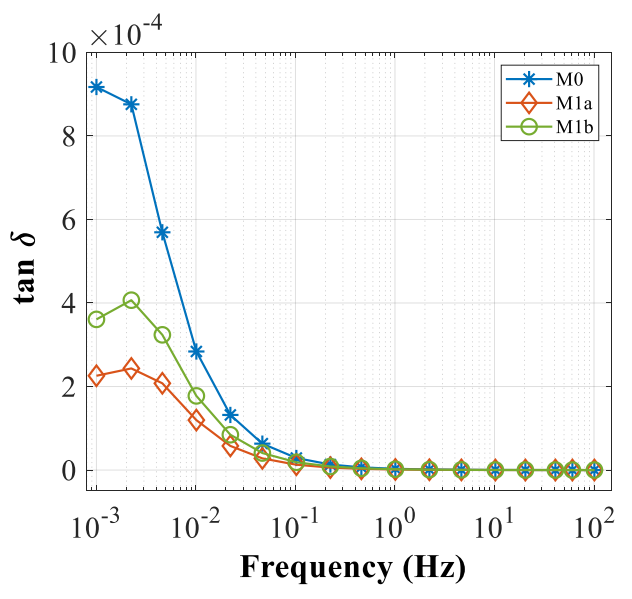

b)

Figure 13. Characteristics of Samicapor recovering tape defect, a) capacitance, b) dissipation factor $\tan \delta$

Spectra of capacitance and dissipation factor $\tan \delta$ provided by Samicapor overlapping tape defects are shown in Figure 13 in comparison with the reference model M0. For frequencies below $20 \mathrm{~Hz}$, one can see that the capacitance decreases normally with the decrease in the Samicapor recovering thickness. Indeed relative permittivity of silicon resin is weaker than that of Samicapor, thus the decrease observed. This behavior is confirmed experimentally by Obame et al [17]. Above 20 $\mathrm{Hz}$, the capacitance seems to increase with the decrease of Samicapor overlapping tape thickness. This behavior could be related to inaccuracy of calculations.

For dissipation factor spectra (Figure 13b), it is seen that $\tan \delta$ decreases with the decrease in Samicapor overlapping tape thickness at low frequency. This behavior is also seen experimentally [17]. However for frequencies above $1 \mathrm{~Hz}$ $\tan \delta$ shows the same characteristic whatever the Samicapor overlapping. Therefore the insulation defect related to the change in Samicapor overlapping tape should clearly be detectable by dielectric spectroscopy.

\section{B. Kapton tearing defect (M2)}

The Kapton tearing defect M2 model geometry is given by Figure 14. In this figure one can see that the void left by the tearing of Kapton is filled by silicone resin since the motor is impregnated with that material. The M2 insolation defect has been simulated with different length of kapton tearing to assess its influence. The length of tearing varied from $1 / 5$ to $5 / 5$ of the total length of the model geometry.
The results (spectra of capacitance and $\tan \delta$ ) from simulations in comparison with reference data of M0 are shown in Figure 15.

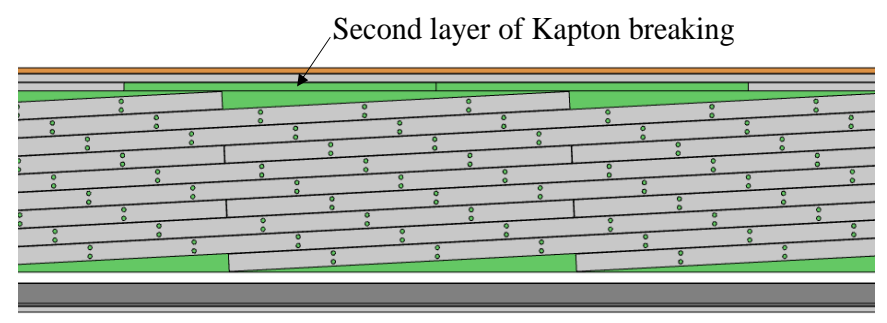

Figure 14. Model geometry of Kapton breaking defect (M2)

In Figure $15 \mathrm{a}$ the spectrum of capacitance shows a plateau for frequencies ranging from $0.1 \mathrm{~Hz}$ to $100 \mathrm{~Hz}$ and this characteristics seems to decrease with the increase of Kapton tearing length which is ranging from $1 / 5$ to $5 / 5$ of the total length of the model geometry. However the change in capacitance recorded remains weak (e.g. $30 \mathrm{pF}$ for a tearing of $80 \%(4 / 5)$ of the total length).

In Figure 15b, we observed that dissipation factor $\tan \delta$ remains almost unchanged except for frequencies below $0.004 \mathrm{~Hz}$ where $\tan \delta$ seems to fall with the increase in the tearing length. However the drop of $\tan \delta$ observed might be related to the computational error as discussed previously.

Therefore the Kapton tearing defect is detectable in theory, however the signature of that defect being dependent to the tearing length, its experimental detection could require increased precision.

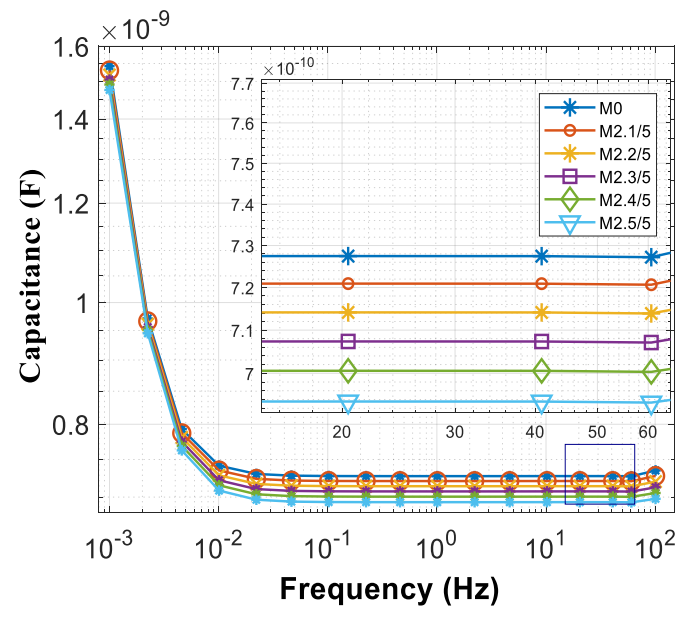

a) 


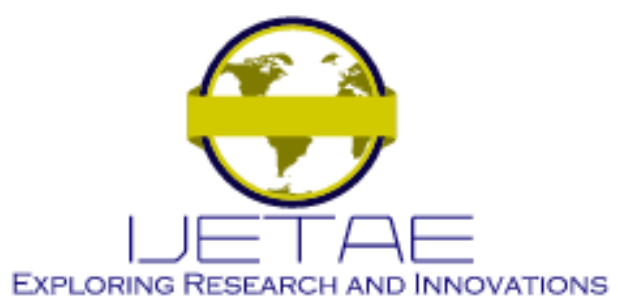

International Journal of Emerging Technology and Advanced Engineering

Website: www.ijetae.com (E-ISSN 2250-2459, Scopus Indexed, ISO 9001:2008 Certified Journal, Volume 12, Issue 01, January 2022)

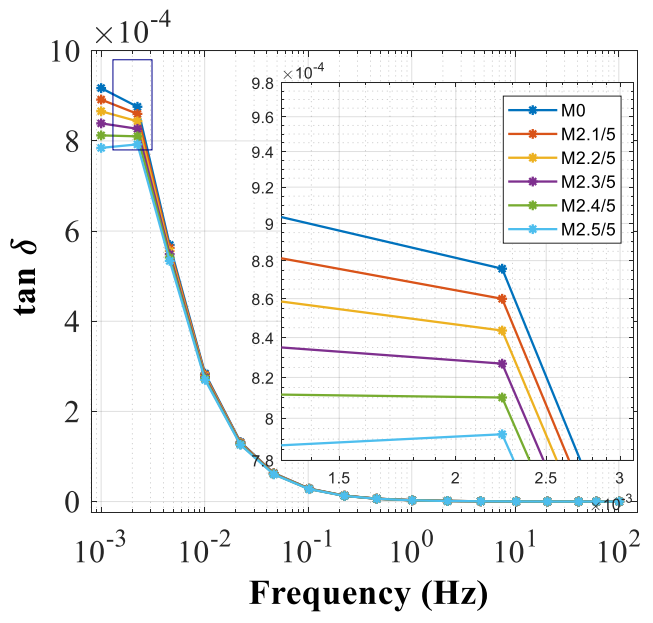

b)

Figure 15. Spectral characteristics of kapton breaking defect, a) capacitance, b) dissipation factor $\tan \delta$

C. Wrong impregnation defect (no vacuum and no pressure phase. M3)

The model geometry used for the simulation of the wrong impregnation defect is seen in Figure 16. This defect leads to the presence of air cavities inside the composite insulation system after impregnation [17].

The spectra of capacitance and $\tan \delta$ from simulations of wrong impregnation defect are seen in Figure 17. The defect conducts to a decrease in capacitance comparatively to the data obtained from the reference M0 in all the frequency range considered. The same behaviour is seen with $\tan \delta$ for frequencies below $0.1 \mathrm{~Hz}$.

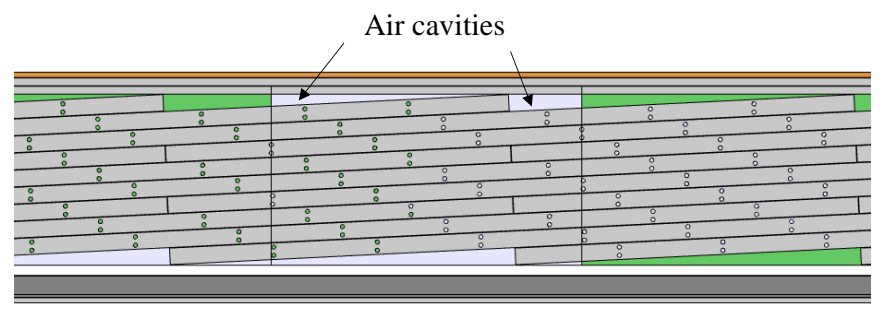

Figure 16. Model geometry of Wrong impregnation defect

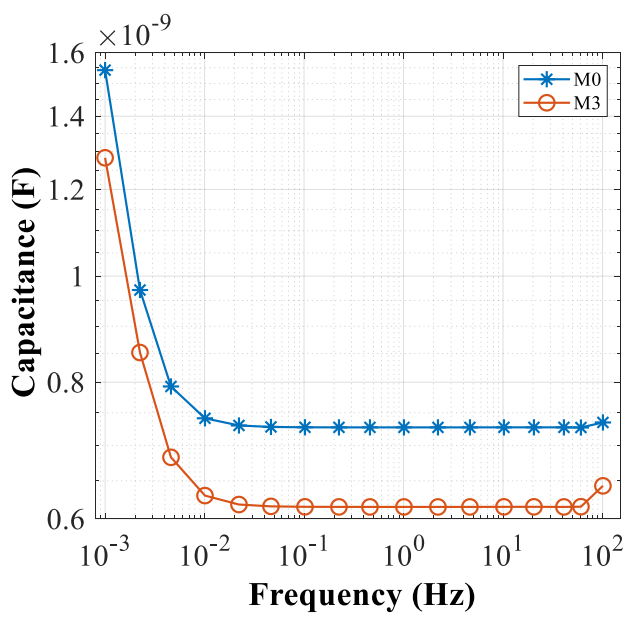

a)

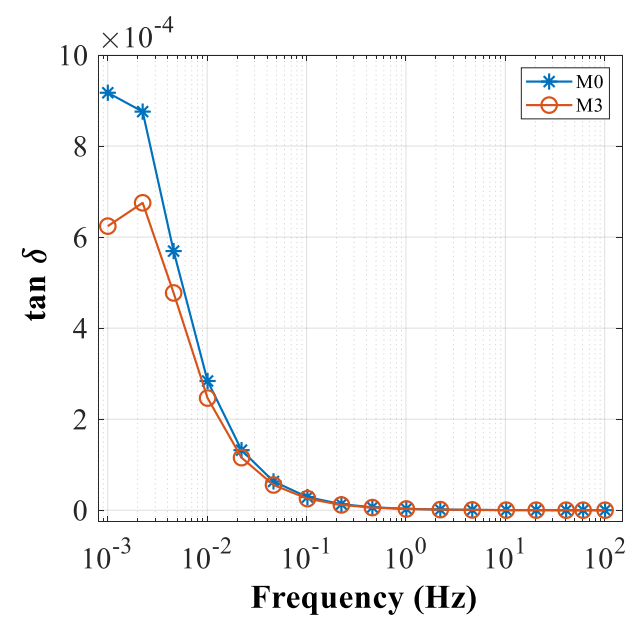

b)

Figure 17. Spectral characteristics of wrong impregnation defect, a) capacitance, b) dissipation factor $\tan \delta$

The capacitance drop (Figure 17a) is logically explained by the presence of air cavities which the dielectric permittivity is lower than that of silicon resin. The decrease in the capacitance observed here is confirmed by experimental measurements as seen in [17]. 


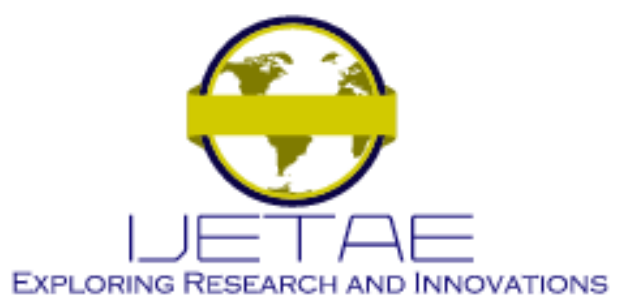

International Journal of Emerging Technology and Advanced Engineering Website: www.ijetae.com (E-ISSN 2250-2459, Scopus Indexed, ISO 9001:2008 Certified Journal, Volume 12, Issue 01, January 2022)

One can observed that dissipation factor decrease for frequencies below $1 \mathrm{~Hz}$. In practice the wrong impregnation defect leads to an increase of the dissipation factor. This is induced by interfacial polarization because of air cavities inside the electrical composite insulation. The spectra of capacitance and tan $\delta$ in comparison with the results obtained from the reference M0 show that wrong impregnation defect is clearly identifiable.

\section{No impregnation defect (M4)}

The model geometry of no impregnation defect is seen in Figure 18. No impregnation induces a strong presence of air cavities inside the insulation system. This leads to a decrease in the capacitance of the composite insulation as seen in (Figure 19a) compared to that of reference M0.

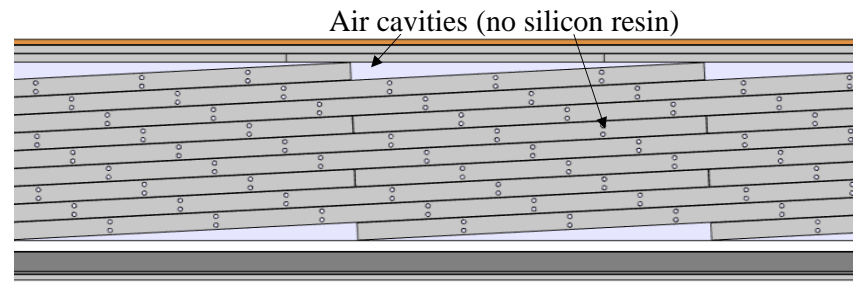

Figure 18. Model geometry of no impregnation defect (M4)

The behaviour observed here is confirmed by experimental measurements carried out by E. Obame et al [17]. And the drop of dissipation factor seen in Figure 19b for frequencies below $1 \mathrm{~Hz}$ is explained by the weaker electric conduction of the model M4 due to air cavities. However measurements [17] show an increase in the $\tan \delta$ due to interfacial polarization. This phenomenon was not taken into account in our computational model. Nevertheless, as seen experimentally the defect M4 is clearly identifiable in theory using the capacitance spectrum.

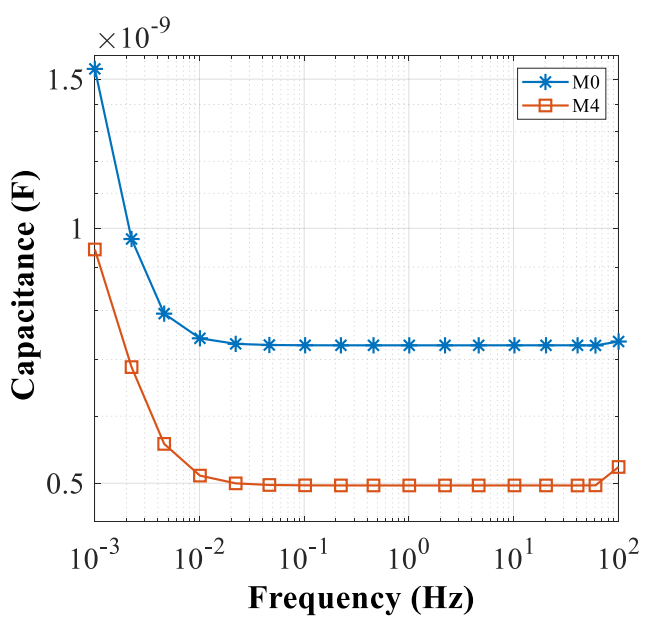

a)

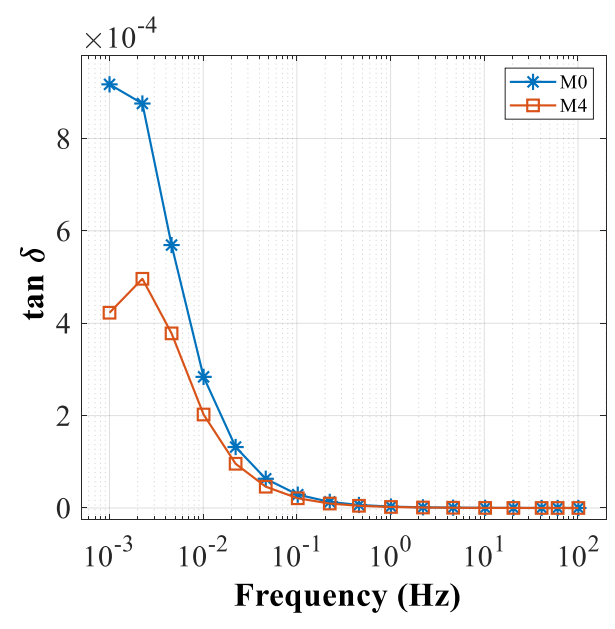

b)

Figure 19. Spectral characteristics of no impregnation defect, a) capacitance, b) dissipation factor $\tan \delta$ 


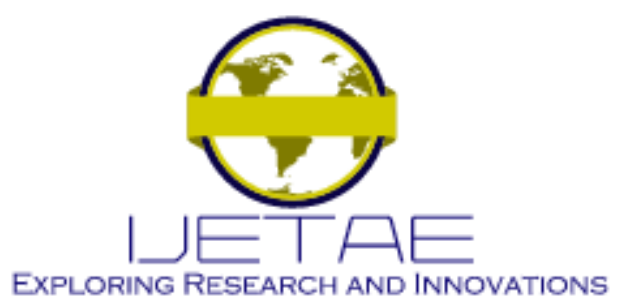

International Journal of Emerging Technology and Advanced Engineering Website: www.ijetae.com (E-ISSN 2250-2459, Scopus Indexed, ISO 9001:2008 Certified Journal, Volume 12, Issue 01, January 2022)

\section{E. No dried before impregnation defect (M5)}

The model geometry of no dried before impregnation defect is given in Figure 20. The stator must be dried to remove moisture before impregnation. In model M5, the procedure of drying has not been conducted [17].

In the model M5 we deal with the extreme case where the composite insulation is moistened, since the structure of the insulation would normally lead to the presence of air cavities inside the insulation after vaporization. This case has conducted to a small decrease in the capacitance spectrum with respect to the reference M0 as we saw with pre-calculation tests. Indeed the density of air cavities for the defect M5 being less than that could be found with the defects M3 and M4, the drop of capacitance was logically lower than that encountered in the latter cases. To observe in addition the influence of humidity on the theoretical capacitance and dissipation factor, air cavities were replaced by water bubbles inside the composite insulation of the M5 model geometry (Figure 20).

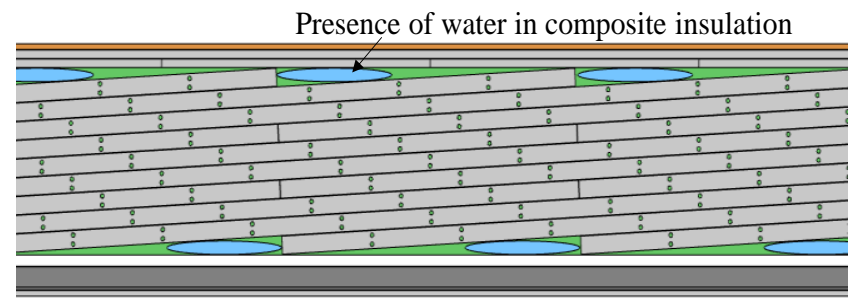

Figure 20. Model geometry of no dried before impregnation defect (M5)

The simulation of defect M5 (Figure 21), showed an increase in the capacitance (Figure 21a) comparatively to that of reference M0. The increase of the capacitance observed is related to the relative permittivity of water bubbles. So the present defect (M5) signature should be clearly identified experimentally. However that identification is related to the density of air cavities or water bubbles inside the composite insulation. The dissipation factor (Figure 21b) is significantly lower than that of reference M0.

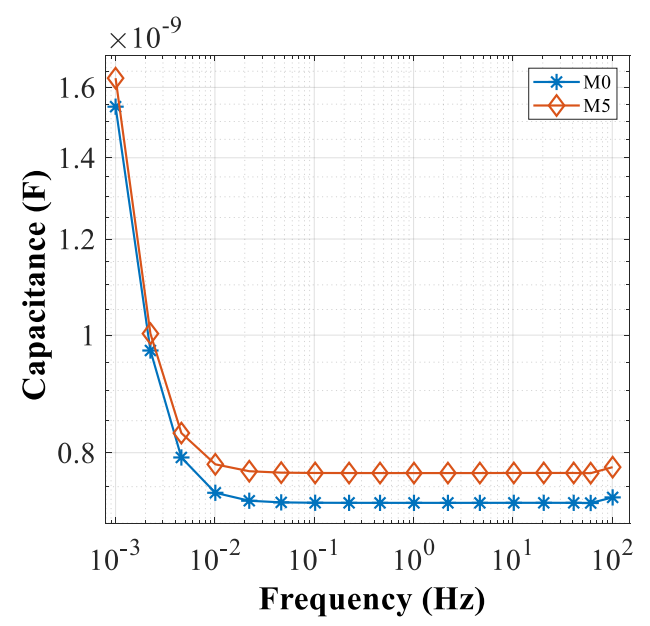

a)

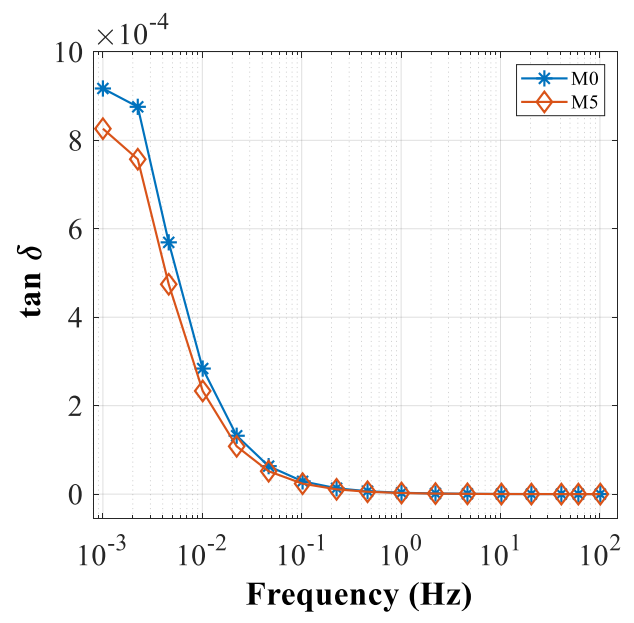

b)

Figure 21. Spectral characteristics of no dried before impregnation defect, a) capacitance, b) dissipation factor $\tan \delta$

F. No moistening of mica tape before wrapping defect (M6)

The model geometry of no moistening of the mica tape before wrapping defect M6 is shown in Figure 22. 


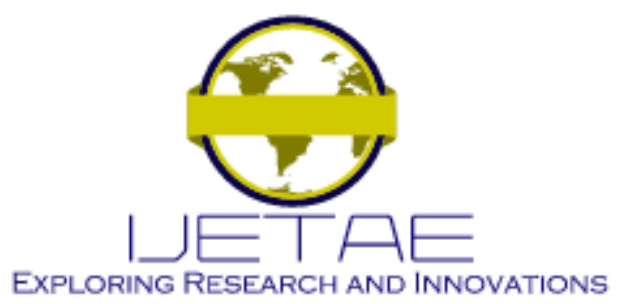

International Journal of Emerging Technology and Advanced Engineering Website: www.ijetae.com (E-ISSN 2250-2459, Scopus Indexed, ISO 9001:2008 Certified Journal, Volume 12, Issue 01, January 2022)

This defect leads to the breakage of the mica tape and the loss of its elementary components (thickness reduction) due to a lack of flexibility so that its wrapping on the conductors of the stator coils is entangled.

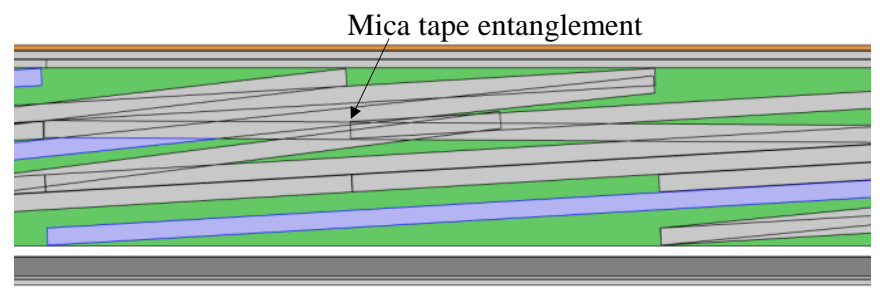

FIGURE 22. Model geometry of no moistening of mica tape before wrapping defect (M6)

Figure 23 shows the spectra of capacitance and the dissipation factor computed from the defect M6. One can observe that the capacitance (Figure 23a) and $\tan \delta$ (Figure 23b) are weaker than the spectra of the reference M0. The drop of the capacitance is explained by the decrease of effective thickness of the Samicapor tape inside the composite insulation of the model M6 since the relative permittivity of mica is higher than that of silicon resin. About the dissipation factor $\tan \delta$, the decrease observed for the frequencies below $1 \mathrm{~Hz}$ could be related to the difference of electrical conductivity of these materials. Indeed the electrical resistivity of silicon resin being higher than that of mica, DC conduction would be higher in M0 than in M6 thus the behaviour observed in Figure 23b.

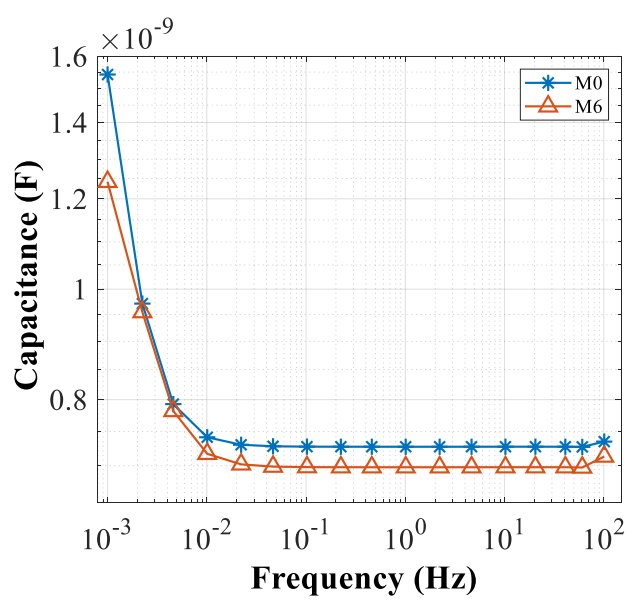

a)

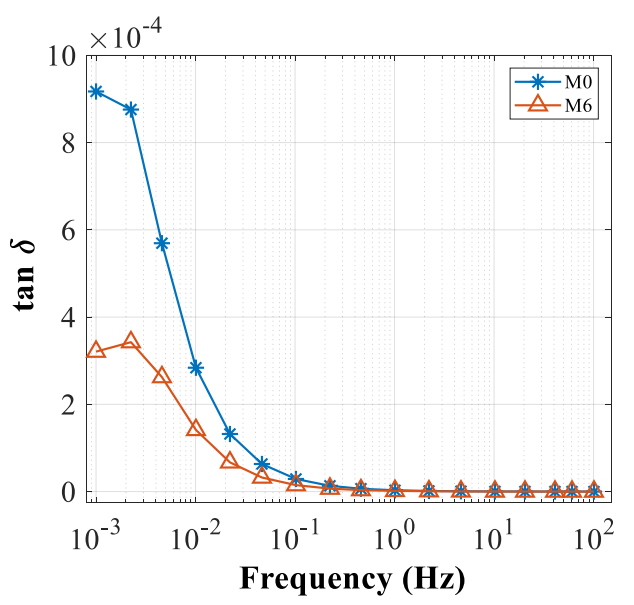

b)

Figure 23. Spectral characteristics of no moistening of mica tape before wrapping defect, a) capacitance, b) dissipation factor $\tan \delta$

\section{Theoretical Sensitivity To The Detection OF DEFECTS}

The Figure 24 shows the spectra of capacitance and dissipation factor of all the potential manufacturing defects in traction motor insulation investigated in comparison with the results from reference $\mathrm{M} 0$.

One can observed that each defect has a specific impact on the capacitance and the dissipation factor of the composite insulation. Therefore all of these defects are theoretically identifiable. However some of them are more easily detectable (M1a, M1b, M3, M4, M5, M6) because of the relatively spectrum deviation of capacitance and or $\tan \delta$ with respect to the reference M0 they present $(3.3 \%$ for capacitance and $13 \%$ for $\tan \delta$ at $0.01 \mathrm{~Hz}$, in worse case). However the defect M2 because of it local nature, is less easy to identify $(0.8 \%$ relative deviation at $0.01 \mathrm{~Hz})$. 


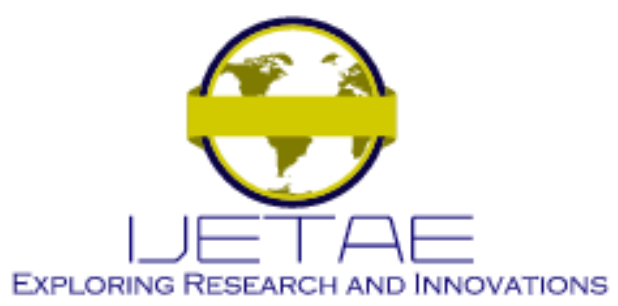

International Journal of Emerging Technology and Advanced Engineering

Website: www.ijetae.com (E-ISSN 2250-2459, Scopus Indexed, ISO 9001:2008 Certified Journal, Volume 12, Issue 01, January 2022)

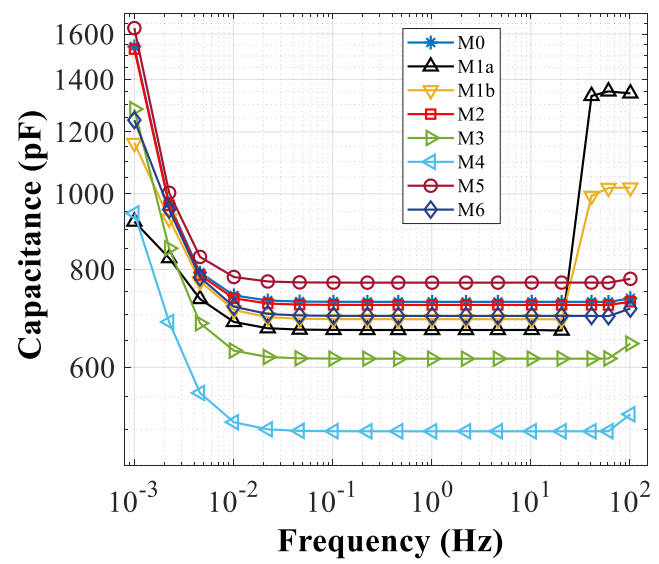

a)

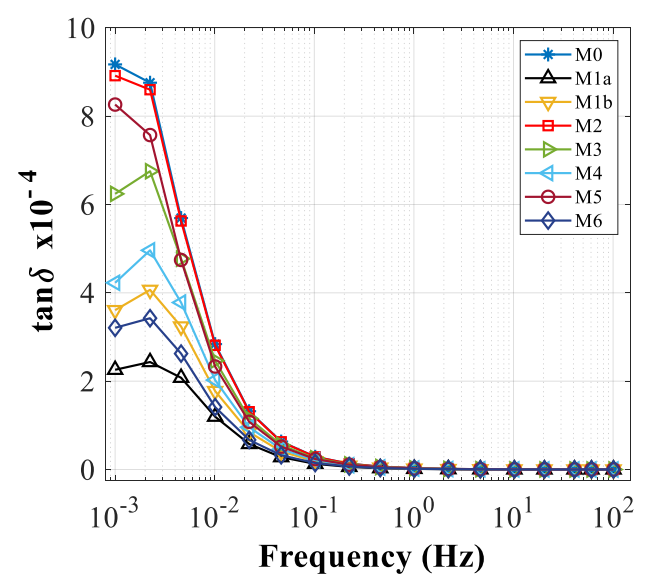

b)

Figure 24. Spectral characteristics of all the defects, a) capacitance, b) dissipation factor $\tan \delta$

The Table VIII and Table IX show respectively the values of the capacitance and $\tan \delta$ of each stator model calculated at $0.01 \mathrm{~Hz}$ and $10 \mathrm{~Hz}$. The present frequencies have been chosen to avoid the possible influence of computational error related to the frequency range (see section III) in the calculation process of the theoretical sensitivity of our method. To highlight that sensitivity, the evaluation of the relative drop of capacitance and $\tan \delta$ with respect to the reference M0 has been calculated for each defect (model stator).
For all artificial defects analysed, it is seen that the relative drop of capacitance is higher than $3.3 \%$ and $4 \%$ for $0.01 \mathrm{~Hz}$ and $10 \mathrm{~Hz}$ respectively, except for the model M2 where the values of $0.8 \%$ and $0.9 \%$ are seen at $0.01 \mathrm{~Hz}$ and $10 \mathrm{~Hz}$ respectively (Table VIII).

TABLE VIII

CAPACITANCE AND RELATIVE VALUES WITH RESPECT TO REFERENCE MODEL MO AT $0.01 \mathrm{~Hz}$ AND $10 \mathrm{~Hz}$.

\begin{tabular}{|l|c|c|c|c|}
\hline \multirow{2}{*}{$\begin{array}{l}\text { Stator } \\
\text { model }\end{array}$} & $\mathbf{C}(\mathbf{p F})$ & $|\boldsymbol{\Delta C} / \mathbf{C}|$ & $\mathbf{C}(\mathbf{p F})$ & $|\boldsymbol{\Delta C} / \mathbf{C}|$ \\
\cline { 2 - 5 } & \multicolumn{2}{|c|}{$\mathbf{0 . 0 1} \mathbf{~ H z}$} & \multicolumn{2}{|c|}{$\mathbf{~ H z}$} \\
\hline M0 & 741.45 & 0 & 727.47 & 0 \\
\hline M1a & 685.63 & 0.075 & 669.57 & 0.079 \\
\hline M1b & 710.28 & 0.042 & 691.30 & 0.050 \\
\hline M2 & 735.08 & 0.008 & 720.92 & 0.009 \\
\hline M3 & 630.15 & 0.150 & 615.41 & 0.154 \\
\hline M4 & 499.79 & 0.326 & 496.98 & 0.317 \\
\hline M5 & 782.61 & 0.055 & 769.87 & 0.058 \\
\hline M6 & 717.12 & 0.033 & 697.96 & 0.041 \\
\hline
\end{tabular}

For dissipation factor $\tan \delta$ (Table IX) the relative drop is higher than $13 \%$ except for the stator model M2 where the values of $1.1 \%$ and $0.4 \%$ were recorded at $0.01 \mathrm{~Hz}$ and 10 $\mathrm{Hz}$ respectively. It is noticed that the values of the calculated $\tan \delta$ for a frequency of $10 \mathrm{~Hz}$ are closed to zero $\left(10^{-7}\right)$, this quantity is fare from experimental data [17] owing to the non-integration in our calculation of the interfacial polarization phenomenon.

TABLE IX

DISSIPATION FACTOR AND RELATIVE VALUES WITH RESPECT TO REFERENCE MODEL MO AT $0.01 \mathrm{HZ}$ AND $10 \mathrm{~Hz}$

\begin{tabular}{|c|c|c|c|c|}
\hline \multirow[t]{2}{*}{$\begin{array}{l}\text { Stator } \\
\text { model }\end{array}$} & $\begin{array}{l}\text { Tan } \delta \\
10^{-4}\end{array}$ & $|\Delta \operatorname{Tan} \delta / \operatorname{Tan} \delta|$ & $\begin{array}{l}\text { Tan } \delta \\
10^{-4}\end{array}$ & $|\Delta \operatorname{Tan} \delta / \operatorname{Tan} \delta|$ \\
\hline & \multicolumn{2}{|c|}{$0.01 \mathrm{~Hz}$} & \multicolumn{2}{|r|}{$10 \mathrm{~Hz}$} \\
\hline M0 & 2.84 & 0 & 2.5 & 0 \\
\hline M1a & 1.20 & 0.577 & 1.00 & 0.600 \\
\hline M1b & 1.78 & 0.373 & 1.50 & 0.400 \\
\hline M2 & 2.81 & 0.011 & 2.49 & 0.004 \\
\hline M3 & 2.46 & 0.134 & 1.8 & 0.280 \\
\hline M4 & 2.02 & 0.289 & 1.7 & 0.320 \\
\hline M5 & 2.33 & 0.180 & 1.9 & 0.240 \\
\hline M6 & 1.41 & 0.504 & 1.2 & 0.520 \\
\hline
\end{tabular}

However, all the defects can be identified at the chosen frequencies $(0.01 \mathrm{~Hz}$ and $10 \mathrm{~Hz})$ except the defect $\mathrm{M} 2$, a local defect, which the detection will need in practice a resolution higher than $0.8 \%$. 


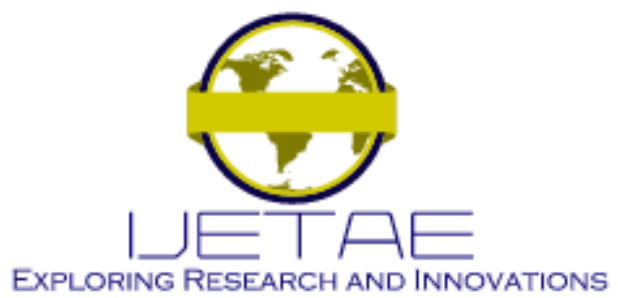

\section{International Journal of Emerging Technology and Advanced Engineering}

Website: www.ijetae.com (E-ISSN 2250-2459, Scopus Indexed, ISO 9001:2008 Certified Journal, Volume 12, Issue 01, January 2022)

\section{CONCLUSION}

Theoretical study of potential manufacturing defects of electrical insulation in medium voltage traction motors was carried out using numerical modelling in frequency domain on COMSOL Multiphysics software. The simulation was based on a simple parallel plane to plane electrical capacitor model with coil conductor as electrode to the potential and iron, the grounded electrode. In our computational model electrical properties of most elementary dielectric materials composing the motor insulation was taken as a function of frequency. The different model geometries specific to each potential defects were highlighted. The results of the simulations shown as spectra of relevant parameters especially capacitance and dissipation factor of each defect were analysed in comparison with the results obtained from the model without defect M0. These results showed that each defect has a spectra of capacitance and dissipation factor specific to it. And the relative deviations observed between the reference model quantities and those specific to defects are particularly appreciable (higher than 3\%) except the case of the defect M2 (kapton tearing with $0.8 \%$ for the capacitance at $0.01 \mathrm{~Hz}$ ). The numerical model presented here shows a good sensitivity on the detection of most defects analysed and could be extended for the theoretical characterization of others composite insulation in low, medium and high voltage systems for prediction purpose.

\section{REFERENCES}

[1] Manés F. Cabanas; Joaquín G. Norniella; Manuel G. Melero; Carlos H. Rojas; José M, Detection of stator winding insulation failures: On-line and off-line tests, IEEE Workshop on Electrical Machines Design, Control and Diagnosis, (WEMDCD) 11-12 March 2013

[2] G.C. Stone, I. Culbert, Review of stator insulation problems in medium voltage motors fed from voltage source PWM drives, International Symposium on Electrical Insulating Materials (ISEIM), June 2014

[3] Greg C. Stone, Howard G. Sedding, Connor Chan, Experience With On-Line Partial Discharge Measurement in High Voltage Inverter Fed Motors August 2017, IEEE Transactions on Industry Applications PP (99):1-1

[4] Waqar Hassan, Ghulam Amjad Hussain, Farhan Mahmood, Salman Amin, Effects of Environmental Factors on Partial Discharge Activity and Estimation of Insulation Lifetime in Electrical Machines, May 2020, IEEE Access PP(99):1-1

[5] Waqar Hassan, Farhan Mahmood, Ghulam Amjad Hussain, Salman Amin, Risk assessment of low voltage motors based on PD measurements and insulation diagnostics, Measurement, February 2021

[6] Saeed Ul Haq and Tariq Bashir, Evaluation of Induction Motor Groundwall Insulation using Infrared Thermography, International Conference on Emerging Technologies, 13 - 14 Nov. 2006
[7] G. C. Stone, Advancements during the past quarter century in online monitoring of motor and generator winding insulation, IEEE Transactions on Dielectrics and Electrical Insulation, vol. 9, no 5, pp. 746-751, Oct. 2002.

[8] Waqar Hassan, Farhan Mahmood, Ghulam Amjad Hussain, Matti Lehtonen, Effects of Environmental Factors on Partial Discharge Activity and Estimation of Insulation Lifetime in Electrical Machines, IEEE Access PP (99):1-1, May 2020

[9] Dimosthenis Verginadis, Athanasios Karlis, Michael Danikas, J.A. Antonino-Daviu, Investigation of Factors Affecting Partial Discharges on Epoxy Resin: Simulation, Experiments, and Reference on Electrical Machines, Energies, October 2021, 14 (20), 2021

[10] Niklas Driendl, Florian Pauli, Kay Hameyer, Influence of Ambient Conditions on the Qualification Tests of the Interturn Insulation in Low-Voltage Electrical Machines, September 2021 IEEE Transactions on Industrial Electronics PP(99):1-1

[11] IEEE Trial-Use Guide to the Measurement of Partial Discharges in Rotating Machinery, IEEE Std 1434-2000, p. i, 2000.

[12] IEEE Recommended practice for testing insulation resistance of rotating machinery, ANSI/IEEE Std 43-2000, 2000.

[13] IEEE Guide for Insulation Maintenance of Large AlternatingCurrent Rotating Machinery (10,000 kVA and Larger), ANSI/IEEE Std 56-1977, p. 0_1, 1977.

[14] IEEE Recommended Practice for Insulation Testing of AC Electric Machinery (2300 V and Above) With High Direct Voltage, IEEE Std 95-2002 (Revision of IEEE Std 95-1977), pp. 1-56, 2002.

[15] IEEE Recommended Practice for Measurement of Power Factor TipUp of Electric Machinery Stator Coil Insulation, IEEE Std 286-2000, pp. i -29, 2001.

[16] IEEE Guide for Testing Turn Insulation of Form-Wound Stator Coils for Alternating-Current Electric Machines," IEEE Std 5222004 (Revision of IEEE Std 522-1992), pp. 0_1 -18, 2004.

[17] E. Obame, Olivier GALLOT LAVALLEE, Gerard TRIPOT. "Detection of artificial insulation defects in medium voltage moto by spectroscopy analysis, IEEE Transaction on energy Conversion, vol.27, June, Issue 2, 2012

[18] T. Tran; Olivier Gallot-Lavallée; Pascal Rain; G. Tripot, The Use of Dielectric Spectroscopy for Detection of Insulation Defects in End Turns of Medium Voltage Motors, IEEE Transactions on Energy Conversion ( Volume: 27, Issue: 4, Dec. pp. 905-911, 2012.

[19] Elysée Obame Ndong, Olivier Gallot-Lavallée et Pascal Rain, Développement de methods d'évaluation de la qualité des isolantions électriques neuves et vieillies des moteurs de traction ferroviaire, Rapport de contrat contrat de collaboration de recherché, Alstom Transports et G2Elab, 2007.

[20] J. C. MAXWELL, "A treatise on electricity and magnetism", 1954, Dover Press New York, Vol. 1.

[21] Van BEEK, L. K. H. "Dielectric behaviour of heterogeneous systems", in Progress in Dielectric (eds J. B. Birks andJ. Hart), 1967 Vol.7, p.69-144, Heywood, London.

[22] J. C. Paul, Polarization of dielectric under the influence of electric and cross-magnetic field, Conference on Electrical Insulation \& Dielectric Phenomena - Annual Report 1985 


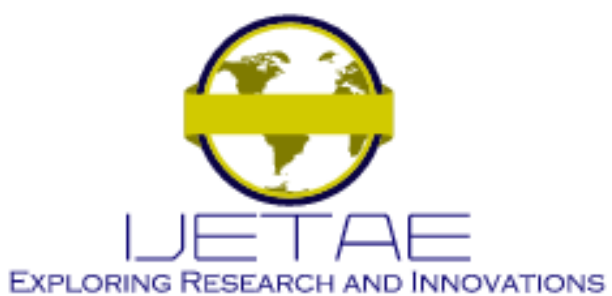

International Journal of Emerging Technology and Advanced Engineering

Website: www.ijetae.com (E-ISSN 2250-2459, Scopus Indexed, ISO 9001:2008 Certified Journal, Volume 12, Issue 01, January 2022)

[23] D.K. Das-Gupta; P.C.N. Scarpa, Polarization and dielectric behaviour of AC aged polyethylene, Proceedings of 1995 International Symposium on Electrical Insulating Materials, 17-20 Sept. 1995, Tokyo, Japan

[24] Tingting Wang, Yu Chen, Zhonghua Li, A simulation study on the interface polarization between the nonlinear dielectrics, Conference: 2015 IEEE 11th International Conference on the Properties and Applications of Dielectric Materials (ICPADM)

[25] G.S. Punekar; G. Thejovathi; N.K. Kishor, Simulation study of Borda's profile \& parallel plane electrode to assess electric field uniformity, in: 8th International Conference on Electromagnetic Interference and Compatibility, 18-19 Dec. 2003.

[26] L. F. Arenas, C. Ponce de León and F. C. Walsh, Critical ReviewThe Versatile Plane Parallel Electrode Geometry: An Illustrated Review, Journal of The Electrochemical Society, Volume 167, Number 2, 2020.

[27] Xu Dong Huang, Sunil Madhukar Bhangale, Peter M Moran, Nikolai L Yakovlev, Jisheng Pan, Surface modification studies of Kapton® HN polyimide films, Polymer International, Volume 52, Issue $7 \mathrm{pp}$. 1064-1069, 2003.

[28] H. Sun, F. Wang, H. Gao, X. Liu, Z. Jin and Z. Hong, AC Breakdown Characteristics of Nomex and Kapton as Insulation Material Used in Pancake Tape Coil Structure for Resistive-Type Superconducting Fault Current Limiter, Applied Physics Research; Vol. 6, No. 6; 2014.

[29] Von Roll Switzerland Ltd, "Mica Tapes (Samicaflex® 366.19)", CH - 4226 Breitenbach, Switzerland, GW 14412 24-03-2006, 366.19, VonRll
[30] Anders Helgeson, Analysis of Dielectric Response Measurement Methods and Dielectric Properties of Resin-Rich Insulation During Processing, Thesis, Kungl Tekniska Högskolan, Department of Electric Power Engineering Division Electrotechnical Design Stockholm, Sweden, 2000-05-26.

[31] R. Blondlot. Détermination de la constante diélectrique du verre, à l'aide d'oscillations électriques très rapides. J. Phys. Theor. Appl., 1891, 10 (1), pp.197-204.

[32] Mohamed A. Al- Amoudi, Determining dielectric constants of glass and thin film using a parallel plate capacitor, International journal of applied science and engineering review, Vol.1 No.4; 2020.

[33] Maxime Rioux, Yannick Ledemi, Jeff Viens, Steeve Morency, Seyed Alireza Ghaffari and Younès Messaddeq, Opticallytransparent and electrically-conductive AgI-AgPO3-WO3 glass fibers, RSC Advances, Vol. 5, Issue 50, pp. 40236-40248, 2015(glass conductivity and permittivity)

[34] Thinh Pham Hong, "Caractérisation et modélisation du comportement diélectrique d'un matériau composite soumis à un viéillissement hydrothermique", Thèse de Doctorat, Université Joseph Fourier Grenoble I, 2005, Grenoble, Ecole Doctorale Electronique, Electrotechnique, Automatique et Traitement du Signal (EEATS).

[35] Robert Fournié et C. Rioux. "Les isolants en électrotechnique Concepts et théories", 1986, Eyrolles, (Paris).

[36] Elysée Obame Ndong, Olivier Gallot - Lavallée, Frédéric Aitken, Application of I.R. Calorimetric Method for Power Losses Measurements in Power Electronics Components and Systems, SSRG International Journal of Electrical and Electronics Engineering Volume 7 Issue 12, 1-9, December 2020. 